\title{
BMJ Open Development and testing of the Youth Alcohol Norms Survey (YANS) instrument to measure youth alcohol norms and psychosocial influences
}

\author{
Sharyn K Burns, ${ }^{1,2}$ Bruce Maycock, ${ }^{1,2}$ Janina Hildebrand, ${ }^{1}$ Yun Zhao, ${ }^{2}$ \\ Steve Allsop, ${ }^{3}$ Roanna Lobo, ${ }^{1}$ Peter Howat ${ }^{1}$
}

To cite: Burns SK,

Maycock B, Hildebrand J, et al. Development and testing of the Youth Alcohol Norms Survey (YANS) instrument to measure youth alcohol norms and psychosocial influences. BMJ Open 2018;8:e019641. doi:10.1136/ bmjopen-2017-019641

- Prepublication history for this paper is available online. To view these files, please visit the journal online (http://dx.doi. org/10.1136/bmjopen-2017019641).

Received 22 September 2017 Revised 22 February 2018 Accepted 17 April 2018
Check for updates

${ }^{1}$ Collaboration for Evidence, Research and Impact in Public Health, School of Public Health, Curtin University, Perth, Western Australia, Australia

${ }^{2}$ School of Public Health, Curtin University, Perth, Western Australia, Australia

${ }^{3}$ National Drug Research Institute, Curtin University, Perth, Western Australia, Australia

Correspondence to

Dr Sharyn K Burns;

s.burns@curtin.edu.au

\section{ABSTRACT}

Objectives This study aimed to develop and validate an online instrument to: (1) identify common alcohol-related social influences, norms and beliefs among adolescents; (2) clarify the process and pathways through which proalcohol norms are transmitted to adolescents; (3) describe the characteristics of social connections that contribute to the transmission of alcohol norms; and (4) identify the influence of alcohol marketing on adolescent norm development. Setting The online Youth Alcohol Norms Survey (YANS) was administered in secondary schools in Western Australia Participants Using a 2-week test-retest format, the YANS was administered to secondary school students $(n=481$, age $=13-17$ years, female $309,64.2 \%$ ).

\section{Primary and secondary outcome measures The} development of the YANS was guided by social cognitive theory and comprised a systematic multistage process including evaluation of content and face validity. A 2-week test-retest format was employed. Exploratory factor analysis was conducted to determine the underlying factor structure of the instrument. Test-retest reliability was examined using intraclass correlation coefficient (ICC) and Cohen's kappa.

Results A five-factor structure with meaningful components and robust factorial loads was identified, and the five factors were labelled as 'individual attitudes and beliefs', 'peer and community identity', 'sibling influences', 'school and community connectedness' and 'injunctive norms', respectively. The instrument demonstrated stability across the test-retest procedure (ICC $=0.68-0.88$, Cohen's kappa coefficient $=0.69$ ) for most variables.

Conclusions The results support the reliability and factorial validity of this instrument. The YANS presents a promising tool, which enables comprehensive assessment of reciprocal individual, behavioural and environmental factors that influence alcohol-related norms among adolescents.

\section{INTRODUCTION}

Adolescent drinking behaviour and the role of social norms

Alcohol consumption among adolescents is a major public health problem worldwide $^{1-3}$ and has been associated with a range of short-term and long-term harms for adolescents and young adults ${ }^{4-8}$ including
Strengths and limitations of this study

- Use of a rigorous mixed methods approach to measure the validity and reliability of the instrument.

- Associations between attitudes and beliefs, social norms and social connectedness explored.

- Instrument provides an ecological perspective suitable for use within community-based interventions.

- Sample included higher proportions of females and students from the younger end of the age range.

- Sample drawn from independent and Catholic schools.

psychological developmental problems. ${ }^{3}$ Use of substances such as alcohol during adolescence can impact brain development, impair judgement and increase likelihood of addiction. ${ }^{9}$ Delaying initiation of alcohol use is an important harm reduction strategy with research demonstrating ongoing negative impact of early initiation of alcohol consumption. ${ }^{10}$ Availability of alcohol, earlier age of consumption or regular use, drinking expectations, peer associations and parental attitudes are key factors in the development of alcohol consumption attitudes and drinking behaviours. ${ }^{71-13}$ These factors can be better understood within the context of social norms, ${ }^{14}$ which have been shown to contribute to shaping personal drinking attitudes and behaviours. 111315

Importance of examining adolescent alcohol norms and psychosocial influences

There remains a lack of understanding as to when norms first manifest in adolescents' beliefs and attitudes towards drinking alcohol, which social contexts or networks contribute most significantly to alcohol use and the potential for some social connections to be protective against harmful alcohol use. A small number of studies examine multiple 


\section{Glossary}

Age norms: expectations regarding the age at which, or ages between which, a certain behaviour is acceptable.

- Descriptive norms: perceptions of what others do that are created through frequently observed behaviours.

- Expectancies:learnt beliefs about the anticipated positive and negative effects of a certain behaviour.

- Injunctive norms: perceptions of the social acceptability of a certain behaviour.

- Permissive norms: perceptions of the extent to which certain behaviours are allowed in a particular social context.

- Sanctions: consequences experienced as a result of deviating from a norm.

- Social norms: expectations shared by a group of people about what is and is not acceptable behaviour.

- Standard drink: one standard drink contains $10 \mathrm{~g}$ of alcohol as per the National Health and Medical Research Council Australian guidelines to reduce health risks from drinking alcohol.

Terminology used in YANS and this paper:

- Item: a statement that the respondent is asked to evaluate based on a specified criterion.

- Scale: a question that is composed of a number of items.

- Assessment measure: the term measure is used in this paper to describe a broad range of assessment tools including individual items, scales and surveys.

- Survey instrument. in this paper, the term instrument or survey instrument is used to describe a whole questionnaire, that is, the Youth Alcohol Norms Survey.

- Dimension: dimension refers to the overarching concepts (eg, norms) under which items that measure related constructs are grouped (eg, descriptive and injunctive norms). In relation to factor analysis, the term factor also represents a dimension.

- Construct. the term construct refers to the different aspects assessed within a dimension (eg, descriptive and injunctive norms).

individual and environmental factors simultaneously, including personal attitudes and expectations, parent, sibling and peer influences, as well as media exposure and impact, ${ }^{16-18}$ but none examine a broad range of factors, and it is not clear how levels of connectedness of youth to different reference groups affect development of drinking patterns.

There are a range of measures examining normative factors influencing alcohol consumption ${ }^{7}{ }^{19-22}$; however, there is a dearth of instruments appropriate for administration in community settings. ${ }^{23}$ Furthermore, Carcioppolo and Jensen ${ }^{24}$ concluded there was a lack of psychometric studies that have assessed the reliability and validity of a broad range of alcohol-related normative constructs. A systematic review of risk and protective factors influencing alcohol-related negative consequences in adolescents found the conceptualisation of constructs varies considerably, which may impact external validity of studies. $^{7}$

While some instruments measure multiple domains, such as the Drug Use Screening Inventory (revised) ${ }^{25} 26$ and Personal Experience Inventory, ${ }^{27}$ these instruments focus on assessing an individual's problem factors rather than considering population-based behaviours. To the best of our knowledge, currently, there is no comprehensive, recognised, social cognitive theory (SCT)-informed instrument that can validly and reliably assess different types of adolescent alcohol norms and related social influences. A psychometrically sound instrument to measure the multiple psychosocial influences involved in the acquisition and transmission of adolescent alcohol norms would contribute to consistency in this field of research. To fill this gap, the Youth Alcohol Norms Survey (YANS) was developed as a data collection tool for a respondent-driven sampling study to investigate three dimensions of interest: individual attitudes and beliefs; norms; and social connectedness among adolescents in community-based settings. ${ }^{28}$

\section{Theoretical framework}

Various theoretical elements of $\mathrm{SCT}^{29}$ were incorporated into the YANS. The adolescent social context encompasses a range of reciprocal influences between an individual and their environment and can help us understand the development of proalcohol norms. ${ }^{29} 30$ According to SCT, complex interactions between environmental, individual/psychological and behavioural factors influence behaviour and behaviour change. SCT assumes that social behaviours are learnt through the observation of behaviours in others, which are consequently perceived as acceptable, modelled, reinforced and internalised..$^{29}$ Consequently, adolescents observe the drinking behaviours of parents, siblings, peers, community members and people in the media that may influence their own drinking behaviours. ${ }^{24}$

In the adolescent alcohol literature, descriptive (perceptions of alcohol consumption) and injunctive (perceived social acceptability of alcohol use) drinking norms of peers have been studied most commonly. ${ }^{31-33}$ These norms predict that an overestimation of, and favourable attitudes towards, drinking alcohol by peers has the effect of increasing personal consumption among young people. ${ }^{11} 31$ However, the perceived prevalence and acceptability of behaviours may also be influenced through modelling behaviours or communication and connection with family, school and the wider community. ${ }^{345}$ Portrayals of behaviours and attitudes supportive of drinking in the media, ${ }^{36}$ and on social networking sites such as Facebook, ${ }^{37}$ can contribute to normalising proalcohol attitudes and consequently drinking behaviour. Moreover, the alcohol literature indicates alcohol expectancies that are linked to norms are established at an early age ${ }^{38}$ and influence alcohol consumption. ${ }^{39}$ Higher levels of perceived drinking and approval of alcohol use of both peers and parents has been associated with positive alcohol expectancies among adolescents, ${ }^{40}{ }^{41}$ as has alcohol advertising. ${ }^{17} 42$

Different social contexts influence norms, which can convey either complementary or contradictory messages of what is acceptable behaviour. Social bonds and perceived identity with certain social groups of 
particular importance are suggested to be key factors in determining whether normative attitudes and behaviours are acted on by an individual. ${ }^{43-45}$ Connectedness to school is associated with a number of positive attributes including delayed alcohol consumption. ${ }^{45-47}$ A systematic review ( $\mathrm{n}=77$ relevant articles) found positive parentchild relationships and parental support and communication to be associated with delayed alcohol initiation and reduced levels of later drinking among adolescents. ${ }^{48}$ Similarly, normative perceptions of reference groups to which an adolescent feels close to or identifies with may have a greater power of influence on drinking behaviour compared with those of distal groups. ${ }^{49}$ School-based studies have found that positive relationships to, and high levels of peer acceptance are associated with conforming behaviour. ${ }^{50}$ However, peer connectedness is not always associated with positive behaviours with some research supporting an increasing likelihood of drinking by an adolescent when they perceive that the majority of their friends consume alcohol, regardless of the strength of social connections. ${ }^{51}$ This paper will (1) detail the development process of the YANS instrument for adolescents aged 13-17 years and (2) describe the testing of the psychometric properties of the instrument, including factorial validity and reliability testing.

\section{METHODS}

\section{Instrument development}

An empirical approach was adopted for the instrument's design. An extensive literature review, repeated reviews by an expert panel $(n=8$, experts in the fields of health promotion, psychology, education, alcohol research and biostatistics), the study reference group ( $\mathrm{n}=8$ key preventative health stakeholders) and seven focus groups with adolescents aged 14-17years in Perth purposively selected from sport and youth clubs $(n=34$; female, $32.4 \%)$ were undertaken to establish content validity. Published assessment measures and qualitative data collection of openended responses from adolescents relevant to normative drinking behaviour were used. Results from the data collection methods informed reduction, modification and development of new questions for constructs where no relevant measures could be located.

Face validity was determined through evaluation by the study reference group and cyclic one-on-one interviews with youth aged 13-17 years $(n=10)$, which enabled evaluation of style, formatting, usability, readability, clarity of language and content. ${ }^{52}$

The final instrument had a Flesch Reading Ease $^{53} 54$ score of 68.8, and a Flesch Kinkaid Grade Level of 5.8. Survey completion was approximately $30 \mathrm{~min}$ and was administered online using Qualtrics survey software (see figure 1).

\section{The YANS}

The YANS was created through an extensive formative development process that was based on the synthesised information collected through the literature review, expert panel reviews, focus groups and instrument pilot testing results and SCT. Three dimensions of interest were included: (1) 'individual attitudes and beliefs'; (2) 'norms'; and (3) 'social connectedness'. Twelve different constructs (drinking intention, alcohol expectancies, drinking attitudes, descriptive norms, injunctive norms, social sanctions, media influence, family connectedness, community connectedness, school connectedness, peer connectedness and group identity) were grouped under these dimensions using established and newly developed items ( $\mathrm{n}=201$ items). Constructs were initially grouped based on the findings of the formative development.

\section{Individual attitudes and beliefs}

Four scales and eight single items were employed to measure individual attitudes and beliefs: drinking intention (likelihood of drinking in the future) (single item) ${ }^{20}$; types of drinks intended to consume if drinking (single item with 11 options); attitudes towards alcohol use related to same-grade students and adults (two Likert-type scales with three items each) ${ }^{21}$; alcohol expectancies (one Likert-type scale with nine items $)^{55}$; ease of obtaining alcohol from parents, friends, older siblings and at an off-premise alcohol sales outlet (one scale with four items); and perceived appropriate age to start drinking alcohol (one open-ended item subsequently coded) ${ }^{56}$ and to receive alcoholic beverages from friends the same age, older friends, older siblings, parents and other adults in general (five open-ended items subsequently coded).

\section{Norms}

The dimension 'norms' consisted of 16 scales and 7 items representing the constructs descriptive norms, injunctive norms, perceived social sanctions and media influence. Questions representing descriptive norms included: perceived number of friends who drink alcohol (single item) ${ }^{57}$; perceived drinking frequency and quantity (two scales with six items each) ${ }^{58}$ and alcohol-related harms (four scales each with nine items) experienced by close friends, same-grade students, older siblings and parents. Injunctive norms assessed: perceived approval of your drinking by close friends, same-grade students and parents for four different drinking situations (three scales with four items each $)^{59}$; importance of social approval regarding your drinking behaviour of close friends, same-grade students, older siblings, mother and father (one Likert-type scale with five items; new measurement); and level of maternal and paternal permissiveness in different drinking scenarios (five single items; three of which were new items). ${ }^{60}$ Perceived social sanctions included: parental consequences if drinking alcohol without their permission (one Likerttype scale with seven items) ${ }^{60}$ and sanctions expected from close friends, same-grade students and siblings when declining an alcoholic drink at a social occasion where most people were drinking (three Likert-type scales with five items each). Media influence consisted of: exposure recall of alcohol promoting advertisements during the past 


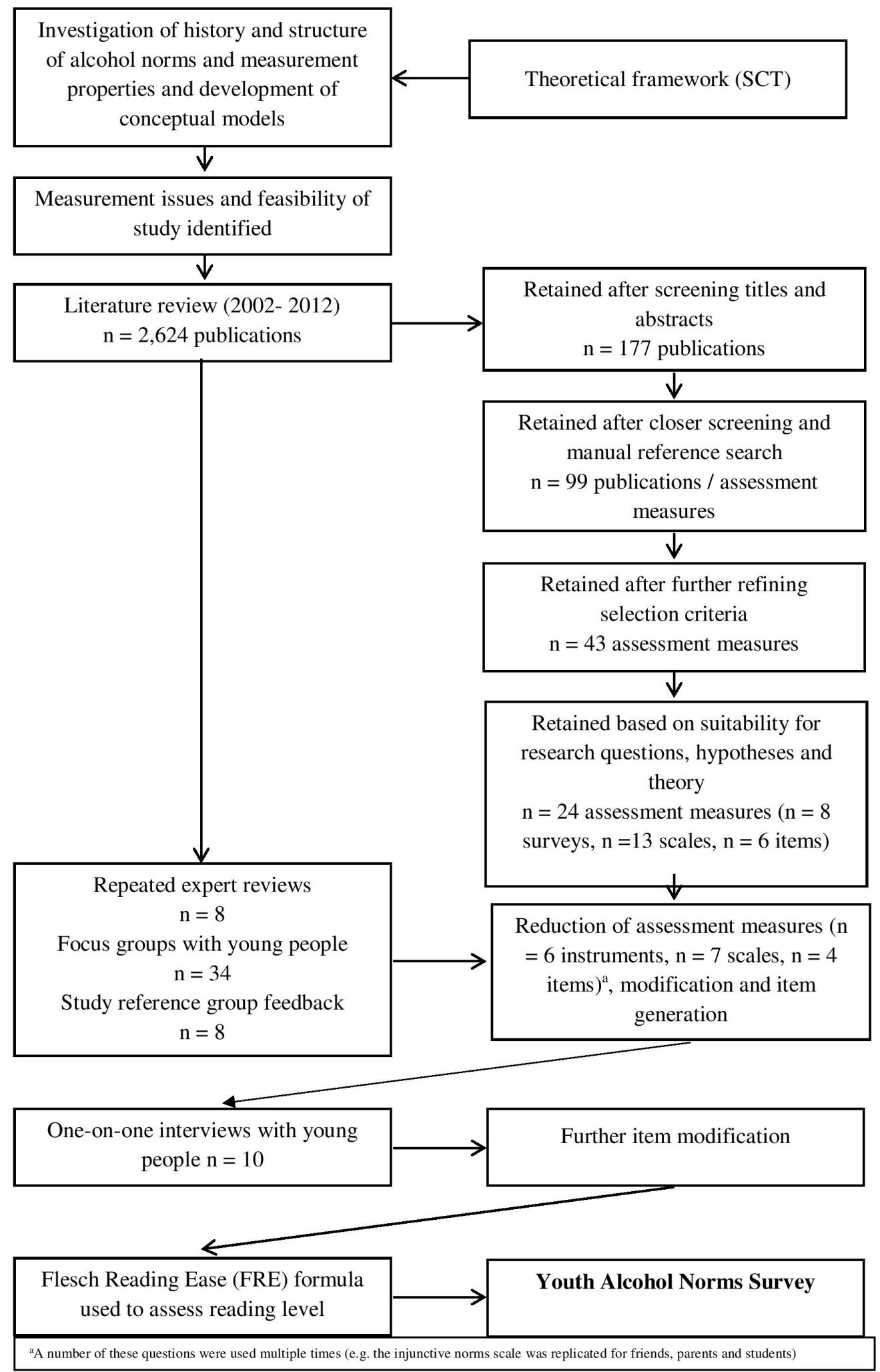

Figure 1 Survey development process.

3 months concerning type of media (one Likert-type scale with 16 items) and type of advertisement recalled (one item with 12 options of different alcoholic beverage types); and the emotional and cognitive response to the most recalled advertisement (advertising effect) (one scale with five items) (new measures).

\section{Social connectedness}

This dimension was assessed using six Likert-type scales measuring: family connectedness (13 items); community connectedness $(10 \text { items })^{61}$; school connectedness $(4 \text { items })^{47}$; peer connectedness $(10 \text { items })^{62}$; sense of belonging ( 6 items); and perceived similarity ( 6 items) of 
alcohol-related attitudes to close friends, students, older youth, siblings, sports club team members and youth community programme members. ${ }^{63}$

For the purpose of the factor analysis, the score of a scale was obtained by summing the individual item scores within an item. To improve factorability of the data set, the items surrounding parental permissiveness (five items) and perceived appropriate age to drink and receive alcohol from others (two items) were summed into one scale as they were considered to represent the same concept. One qualitative item (recall of alcohol brand types) was excluded from analysis.

Figure 2 presents an overview of the measurement pool included in the YANS. Questions about demographic characteristics and individual drinking behaviours were also included and were adapted from the Australian Secondary School Students' Alcohol and Drugs Survey. ${ }^{64}$

\section{Data collection}

A sample of adolescents aged 13-17years were recruited at six purposively selected Independent and Catholic secondary schools in Perth, Western Australia. To reduce bias, students were recruited via class with all students in the class invited to participate. Of students recruited $(\mathrm{n}=588), 481$ (64.2\% females) consented and completed the YANS at baseline (participant rate: $81.8 \%$ ). To assess test-retest reliability, 402 students $(69.2 \%$ females $)$ of the baseline sample completed the YANS again 2 weeks later (response rate of $83 \%$ over the two time intervals). The methodology employed for recruitment has been described elsewhere. ${ }^{28}$

\section{Patient and public involvement}

The school students involved in this study were not involved in the development of the research question, the outcome measures or study design. However, the focus of the study and the development of the instrument was informed via student focus groups and expert panel reviews. ${ }^{28}$ Participants were recruited through schools as described above. There are no plans to disseminate results to study participants directly; however, results will be published in open-access peer-review publications.

\section{Statistical analysis}

\section{Exploratory factor analysis (EFA)}

EFA was used in this study to: (1) ascertain the distinct underlying factor structure of the YANS to explain the complex pattern of correlations within the set of observed variables; (2) reduce the number of variables observed in the YANS; and (3) demonstrate the dimensionality of YANS and describe the most important characteristics when classifying groups of variables.

Baseline survey respondents $(n=481)$ were subjected to the EFA, which achieved 'very good' ${ }^{65}$ sample size adequacy for conducting EFA. Given that factor analysis is robust to the departure of normality assumption, ${ }^{66}$ the original observed variables were used in the EFA as attempts of natural logarithm and other transformations did not improve normality.

The suitability and appropriateness of conducting the EFA was assessed by an inspection of the correlation matrix for a factorability of greater than 0.3 , a Bartlett's test for a significant sphericity test with a $\mathrm{p}$ value of $<0.05^{67}$ and of a Kaiser-Meyer-Olkin (KMO) measure for a sampling adequacy of greater than $0.7 .{ }^{68}$ Principal axis factoring (PAF) with oblique rotation method was used to examine the factor structure and extract initial solutions. Eigenvalues $>1.0^{69}$ and scree test ${ }^{70}$ were initially used to obtain the number of factors retained to achieve the final interpretable factor structure of the YANS. Factor loading cut-off point for variables of $0.3^{69}$ with at least three variables per factor ${ }^{72}$ was considered in the EFA to identify a practical interpretable independent factor. Variables were assigned to factors with a higher loading if cross-loading existed, and the finalised factors were named based on summarised characteristics of the variables loaded.

\section{Test-retest reliability}

Test-retest reliability was assessed by intraclass correlation coefficient (ICC) for continuous and Cohen's kappa for categorical variables. For sound reliability, an ICC of $>0.6$ and kappa values of $>0.7$ is recommended. ${ }^{52}$ All data analyses were performed using IBM SPSS Statistics (V.22).

\section{RESULTS}

\section{Demographics and drinking behaviour}

Students $(\mathrm{n}=481 ; 35.8 \%$ male, $64.2 \%$ female) from grades 9-11 (age 13-17 years) from six schools participated at baseline. Three schools were coeducational, two were boys' schools and one was a girls' school. Half of the study sample was recruited at the girls' school $(\mathrm{n}=238,49.5 \%)$. The majority of participants were aged 13-14 years $(\mathrm{n}=391 ; 81.5 \%)$ and spoke English as their main language at home $(n=399,83.0 \%)$. Five per cent of the total sample identified as Aboriginal and/or Torres Strait Islander and almost three-quarters of respondents reported living in high advantaged areas $(n=347,73.5 \%)$. Overall, $74.4 \% \quad(\mathrm{n}=358)$ of participants reported to have ever had an alcoholic drink in their lives; however, 39.1\% $(n=188)$ of the sample reported to have only had a few sips of alcohol. When asked about recent alcohol consumption, $18.3 \%(n=89)$ of the sample reported to have had at least one standard drink in the last 4 weeks. There was no significant difference in alcohol consumption in the past 4 weeks between age groups $(\mathrm{p}=0.248)$.

\section{Exploratory factor analysis}

\section{Dimensionality of the YANS instrument}

PAF extraction is the preferred method for non-normally distributed data, hence was used to explore the structure of the YANS with different rotation. ${ }^{66} 73$ Oblimin rotation method was employed. ${ }^{73}$ 


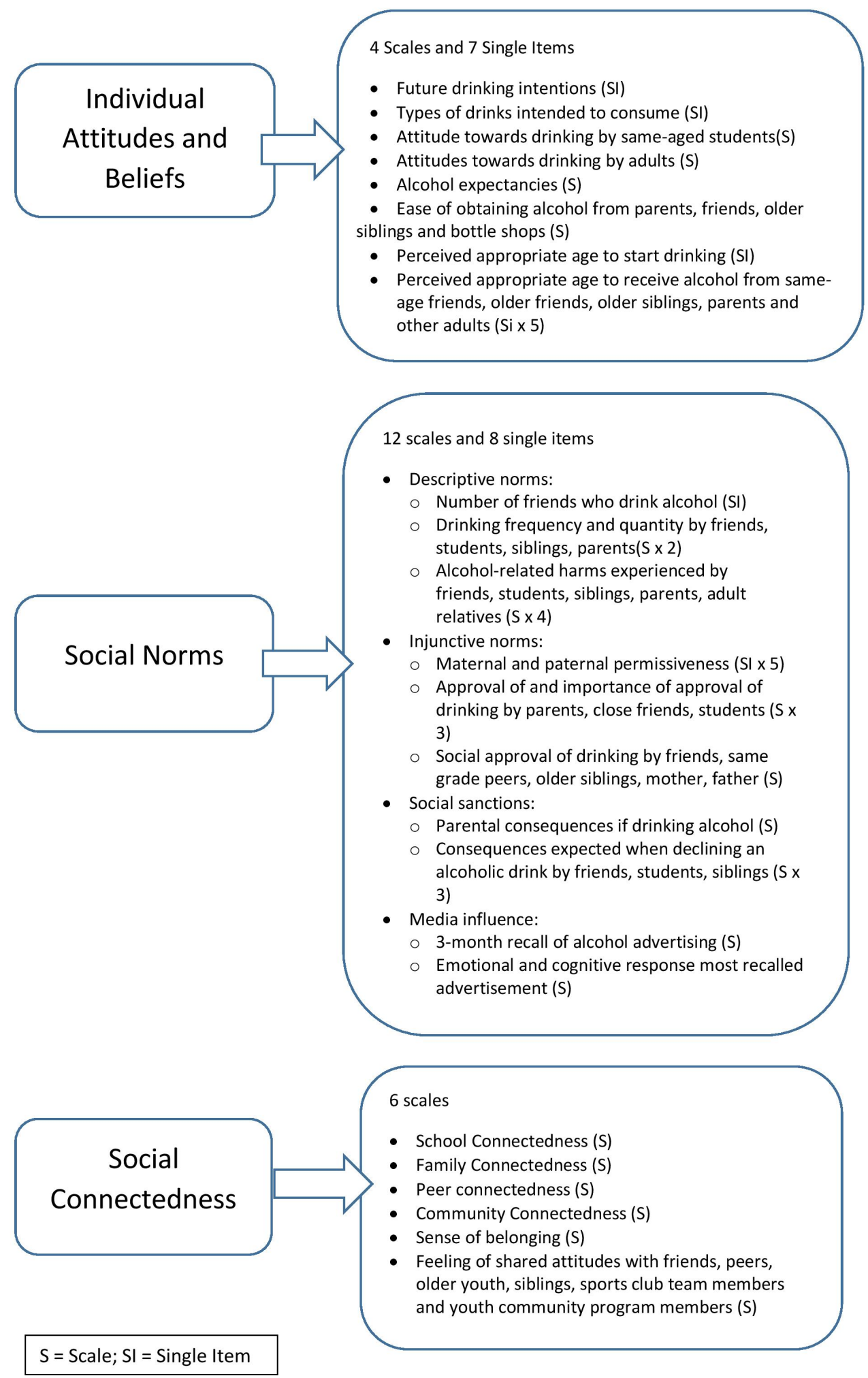

Figure 2 Pool of measures included in the development of the YANS.

An unconstrained factor analysis of variables was attempted that determined five factors should be retained, producing a five-factor solution that explained up to $41.8 \%$ of total variance. However, one factor of this structure contained only two variables and explained less than $5 \%$ of total variation. Forced four factor and three factor solutions were computed; however, the five factor solution represented the best model. Therefore, although one factor only included two variables, this factor was retained given the nature of these variables that both related to sibling influence. Three variables (perceived harms (friends, students, siblings, parents, other 
Table 1 Results of the final five-factor solution of the YANS according to principal axis factoring with oblique rotation



YANS, Youth Alcohol Norms Survey.

adults), consequences students and social approval) loaded low $(<0.3)$ on each factor and did not correlate well (with a lower than 0.3 item total correlation) with the total scale score and were eliminated.

Table 1 displays the final results of the five-factor solution along with the rotated factor loadings. With a value of $0.79 \mathrm{KMO}$ measure of sampling adequacy and a highly significant Bartlett's test of sphericity $\left(\chi^{2}=484.898\right.$, $\mathrm{p}<0.001)$, the five-factor solution explained $41.8 \%$ of the total variance, suggesting meaningful dimensions. The first extracted factor, 'individual attitudes and beliefs', contained nine variables (and explained $14.8 \%$ of the 
total variance). The second extracted factor, 'peer and community identity', loaded with eight variables and accounted for an additional $11.6 \%$ of the total variance. The third extracted factor, 'sibling influence', included two six variables (and attributed to further $6.6 \%$ of the total variance). The fourth factor 'family and school connectedness' attributed to $4.8 \%$ of the variance and included four variables. The final factor, 'injunctive norms', consisted of four variables (and attributed to $4.1 \%$ of the variance). Most variables had substantial loadings on one factor $(>0.4)$, and two variables cross-loaded on more than one factor and were assigned to the higher loaded factor.

\section{Test-retest reliability}

The test-retest reliability of variables representing 'individual attitudes and beliefs' (ICC $=0.68-0.84$, Cohen's kappa 0.69), 'peer and community identity' (ICC $=0.69$ 0.80 ), 'sibling influences' (ICC $=0.73-0.85$ ) was moderate to excellent. The test-retest for the variables representing 'school and community connectedness' (ICC $=0.46-0.88)$ and injunctive norms (ICC $=0.47-0.76$ ) included several variables with lower ICC; however, the majority of these variables ranged from moderate to excellent (table 2).

\section{DISCUSSION}

In this paper, the development process of the YANS instrument for assessing multiple influences on drinking behaviours, norms and attitudes among adolescents aged 13-17 years were detailed and the key psychometric properties of the instrument, including the underlying factor structure and test-retest reliability. The instrument was found to have a good factor structure with meaningful components and robust factorial loads for most variables. In view of the results obtained from the EFA, this study showed that the YANS had a clear and meaningful structure with five factors, each measuring a unique dimension.

'Individual attitudes and beliefs' included nine variables: drinking intentions, attitudes towards drinking by sameaged peers and by adults, future drinking intention, ease of access to alcohol, perceived age to start drinking, perceived frequency of drinking of others, perceived parental permissiveness, alcohol expectancies, and advertising influence. 'Peer and community identity' consisted of eight variables: identity to other sameaged students, identity to community, identity to sports club/ team, identity to older teens, peer connectedness, advertisement recall and community connectedness. Only two variables were loaded onto the 'sibling influences' factor: identity to siblings and perceived consequences of alcohol refusal by siblings; however, this was retained due to the recognition of the importance of considering sibling influences. ${ }^{74}$ The four variables loading on 'school and community connectedness' were familyconnectedness, school connectedness, perceived drinking quantity of others and perceived parental consequences. The final factor 'injunctive norms' included perceived approval of drinking by friends, perceived approval of drinking
Table 2 Intraclass correlation coefficient (ICC) and Cohen's kappa of factor variables

\begin{tabular}{|c|c|}
\hline Factor 1: individual attitudes and beliefs & ICC \\
\hline $\begin{array}{l}\text { Attitudes towards drinking by same-age } \\
\text { peers }\end{array}$ & 0.813 \\
\hline Attitudes towards drinking by adults & 0.767 \\
\hline Perceived age norms & 0.803 \\
\hline Drinking intention & $0.694^{*}$ \\
\hline Perceived ease of access to alcohol & 0.840 \\
\hline Perceived drinking frequency others & 0.682 \\
\hline Perceived parental permissiveness & 0.782 \\
\hline Advertising influence & 0.711 \\
\hline Alcohol expectancies & 0.747 \\
\hline \multicolumn{2}{|l|}{ Factor 2: peer and community identity } \\
\hline Identity to other same-age students & 0.687 \\
\hline Identity to community & 0.726 \\
\hline Identity to sports club/team & 0.826 \\
\hline Identity to older teen & 0.739 \\
\hline Identity to friends & 0.713 \\
\hline Peer connectedness & 0.832 \\
\hline Advertisement recall & 0.749 \\
\hline Community connectedness & 0.801 \\
\hline \multicolumn{2}{|l|}{ Factor 3: sibling influences } \\
\hline Identity to siblings & 0.853 \\
\hline $\begin{array}{l}\text { Perceived consequences of alcohol refusal } \\
\text { by siblings }\end{array}$ & 0.732 \\
\hline
\end{tabular}

Factor 4: school and community

connectedness

\begin{tabular}{ll}
\hline Family connectedness & 0.888 \\
\hline School connectedness & 0.868 \\
\hline Perceived drinking quantity of others & 0.564 \\
\hline Perceived parental consequences & 0.456 \\
\hline Factor 5: injunctive norms & \\
\hline $\begin{array}{l}\text { Perceived approval of drinking by friends } \\
\text { Perceived approval of drinking by students }\end{array}$ & 0.633 \\
\hline $\begin{array}{l}\text { Perceived approval of drinking by parents } \\
\text { Perceived consequences of alcohol refusal }\end{array}$ & 0.469 \\
\hline by friends & 0.758 \\
\hline
\end{tabular}

${ }^{*}$ Cohen's kappa as categorical item.

by students, perceived approval of drinking by parents and perceived consequences of alcohol refusal by friends.

Although the final factor structure varied from our original theoretical dimensions, the final five factors represent distinctive factors. Almost all variables loaded onto one factor. The exceptions included school connectedness, which was also loaded onto 'peer and community identity' and perceived consequences of alcohol refusal by friends, which was also loaded onto 'individual attitudes and beliefs'. 
Several variables (appropriate age to receive alcohol from others, perceived alcohol harms of others, perceived consequences of alcohol refusal by same-age students and social approval) were removed during the process of the EFA due to their poor fit in the factor structure solution. As the sample consisted predominantly of younger adolescents, it is possible that the sanctions-related and alcohol-related harms items performed poorly as only a small proportion of our sample reported experience with drinking alcohol. Experienced harms questions are widely used with young adults $^{8}{ }^{74-77}$ and may be more appropriate for older school-aged adolescents, especially in relation to perceptions of harms of others. Social approval was loaded onto four of the five factors; however, factorial loads were low $(<0.3)$. These variables represent important concepts underlying alcohol consumption behaviours; therefore, it is recommended to refine the wording and structure of the excluded items to improve clarity and ease of understanding and retest these items in future studies.

The five-factor structure of YANS will enable the measurement of the complex interaction between environmental, individual/psychological and behavioural influences consistent with SCT. The factors will support the measurement of the influence of the behaviour of significant others, especially peers and siblings and of ecological influences associated with school and community on behaviour change. ${ }^{29}$ Furthermore, the YANS enables measurement of peer and community identity, key aspects of ecological influences ${ }^{78}$ and important components of SCT. ${ }^{29}$

The focus on injunctive as well as descriptive norms, in addition to broader ecological factors associated with school and community, enable theoretical models such as $\mathrm{SCT}^{29}$ to be adequately measured. The predominant focus of current instruments on descriptive norms and the need to include injunctive norms when exploring adolescent alcohol consumption has been highlighted. ${ }^{79}$ Furthermore, a systematic review of the literature $(n=52$ studies) found greater focus on risk as opposed to protective factors associated with alcohol consumption among adolescents suggesting a need for a more balanced approach. ${ }^{7}$ The YANS addresses a recognised need to include a community-based focus ${ }^{23}$ and to include a broad range of normative constructs ${ }^{24}$ while enabling the application of SCT.

This study found five factors which are useful to inform community and school based intervention emerged. While three categories (individual attitudes and beliefs, social norms and social connectedness) were used to initially select and group questions, it is recognised that EFA aims to reveal latent variables. ${ }^{73}$ EFA, using PAF is considered and more robust and appropriate analysis to use compared with principal component analysis, which does not discriminate between shared and unique variance. ${ }^{72}$ Each obtained factor appeared to measure a unique dimension indicating the YANS measured five separate dimensions of youth alcohol norms and multiple psychosocial influences.
The necessity of tailoring adolescent alcohol interventions towards a specific target group has been highlighted in previous alcohol research. ${ }^{77} 70-82$ This instrument provides the capacity to measure adolescent attitudes, beliefs and norms at an individual, community and school levels, which will enable informed decisions regarding intervention development.

Test-retest reliability of the instrument was high, with most variables achieving moderate to high values (ICC 0.63-0.89, Cohen's kappa=0.69), supporting its stability across repeated measurements. Three variables, perceived parental consequences (ICC 0.46), perceived drinking quantity of others (ICC 0.56 ) and perceived approval of drinking by parents (ICC 0.47 ), reported low ICC. As the majority of students in this study were young adolescents, low reliability of these scales may be associated with lack of experience of alcohol consumption that may impact perceptions of others behaviours and approval; however, further research to test the instrument in a community-based setting would support evidence for this tool.

\section{Study limitations and conclusions}

Recruitment coincided with the end of the school year, hence restricting access to older students and the proportion of schools willing to be involved. Although the sample size was large, it consisted of a larger proportion of females $(n=309,64.2 \%)$ and younger adolescents (13-14 years; $\mathrm{n}=391,81.5 \%$ ). Although alcohol consumption was relatively low, ever drinking $(74.4 \%)$ was similar to the most recent Australian survey of secondary schoolaged students (12-17 years) that found $74 \%$ to have ever tried an alcoholic drink. ${ }^{83}$ In this study, $18.3 \%$ of students reported to have drunk at least one standard drink in the past 4 weeks compared with $29 \%$ in the Australian survey. ${ }^{83}$ Alcohol-related questions have the potential to be subject to issues of social desirability; however, comparisons with the National study, ${ }^{83}$ considering the younger cohort of this study, suggests data are reliable.

Schools in this sample were drawn from Catholic and independent schools that may bias the findings. In Australia, an increasing number of students in Catholic schools have little connection to the religious community. ${ }^{84}$ One Sydney-based study found $25 \%$ of students attending Catholic schools were not Catholic. ${ }^{85}$ Independent schools in Western Australia represent a diverse range of students from all social and ethnic backgrounds. ${ }^{86}$ Furthermore, Australian research suggests risky alcohol consumption impacts a diverse range of people regardless of religion. ${ }^{87}$

While these factors may have created a sample bias, the overall robust performance of the instrument among younger age groups with little alcohol consumption experience suggests that testing it with older adolescents may in fact improve the instrument's psychometric properties as one may expect more normally distributed data. However, the younger cohort may also impact generalisability. Furthermore, due to the time constraints placed on us by the schools, no other scales were tested in this 
study to compare the instrument's ability to discriminate between established scales measuring similar or different concepts. It is recommended the instrument be validated against other existing measures to ascertain divergent and convergent validity. This study tested partially discriminant validity by assessing whether each of the items/scales represented a unique dimension. Due to the lack of a comprehensive valid and reliable instrument to assess alcohol-related norms, connectedness and psychosocial influences among adolescents aged 13-17 years, along with the challenges associated with developmental differences and levels of exposure to alcohol among this age group, a full-scale predictive validity assessment of the YANS should be conducted in a future investigation. We acknowledge that combining the items into five overarching concepts may lose information about which aspects are contributing the most to alcohol use, thus further analysis might examine the reliability, predictive validity and age appropriateness of individual items. Future studies using the survey instrument would still be able to use the individual items to compare the influence of the different factors on drinking behaviour. The findings of the results from the EFA, correlation coefficients, internal consistency and test-retest reliability are promising, supporting the psychometric performance of the instrument.

The YANS facilitates the examination of various facets of reciprocal influence that may affect adolescent health behaviours related to alcohol use, including constructs that have received limited attention in previous tools, such as descriptive and injunctive norms for a wide range of reference groups, influence of alcohol advertising, social connectedness and group identity. This multidimensional and theory-based instrument is comprehensive with satisfactory psychometric properties. As this paper describes the first validation study on the YANS, it is desirable that additional psychometric analyses be conducted for strengthening its performance. Notwithstanding, the YANS represents an important contribution to existing measures for the assessment of alcohol-related norms and psychosocial influences among young people, given the current lack of examples that are comprehensive, psychometrically sound and able to be applied in community settings. The instrument may be used to screen subpopulations and identify which psychosocial constructs and/ or demographic groups could receive future mediation. This would be beneficial in aiding researchers and practitioners to plan interventions and in demonstrating to policy makers the influences on adolescent harmful drinking. The instrument can contribute to the design of specific comprehensive community-based and schoolbased interventions that have the potential to postpone drinking initiation and reduce risky drinking, ultimately leading to improvements in adolescent health outcomes.

Acknowledgements The authors would like to thank Dr Jonathan Hallett and $\mathrm{Dr}$ Jude Comfort for their contributions to the design and implementation of the study. We would also like to thank Ms Kathryn Delroy and Ms Lucinda Watts for their help with data collection. We would like to thank the school students and the expert panel for their time and contribution.
Contributors BM was chief investigator, conceived and designed the overarching study proposal, secured funding and guided all aspects of the study. SKB coordinated the development of this manuscript including conducting analysis drafting versions of the manuscript. PH, SKB, SA and RL guided the instrument development study. JH led the design of the instrument development study and data collection, performed some data analysis and drafted early versions of the manuscript. YZ developed the statistical analyses plan and guided all aspects of data analysis. SKB, PH, SA and RL were investigators of the study. All authors critically revised the manuscript and approved the final version of the manuscript.

Funding The Youth Alcohol Norms Survey study received funding from the Western Australian Health Promotion Foundation (Healthway) (grant number: 20331).

Competing interests None declared.

Patient consent Obtained.

Ethics approval This study was approved by the Curtin University Human Research Ethics Committee (approval number: HR-25/2012).

Provenance and peer review Not commissioned; externally peer reviewed.

Data sharing statement The datasets generated during and/or analysed during the current study are available from the corresponding author on reasonable request.

Open Access This is an Open Access article distributed in accordance with the Creative Commons Attribution Non Commercial (CC BY-NC 4.0) license, which permits others to distribute, remix, adapt, build upon this work non-commercially, and license their derivative works on different terms, provided the original work is properly cited and the use is non-commercial. See: http://creativecommons.org/ licenses/by-nc/4.0/

(c) Article author(s) (or their employer(s) unless otherwise stated in the text of the article) 2018. All rights reserved. No commercial use is permitted unless otherwise expressly granted.

\section{REFERENCES}

1. World Health Organization:. Global status report on alcohol and health. Geneva: World Health Organization, 2011.

2. Jansen SC, Haveman-Nies A, Bos-Oude Groeniger I, Groeniger B-O I, et al. Effectiveness of a Dutch community-based alcohol intervention: Changes in alcohol use of adolescents after 1 and 5 years. Drug Alcohol Depend 2016;159:125-32 https://doi.org/.

3. Australian Institute of Health and Welfare. National Drug Strategy Household Survey detailed report 2013. Drug statistics series no. 28. Cat. no. PHE 183. In. Canberra AlHW 2014.

4. Kuntsche E, Gmel G. Alcohol consumption in late adolescence and early adulthood--where is the problem? Swiss Med Wkly 2013;143:w13826 https://doi.org/.

5. Hingson RW, Zha W. Age of drinking onset, alcohol use disorders, frequent heavy drinking, and unintentionally injuring oneself and others after drinking. Pediatrics 2009;123:1477-84 https://doi.org/.

6. Rehm J, Mathers C, Popova S, et al. Global burden of disease and injury and economic cost attributable to alcohol use and alcohol-use disorders. Lancet 2009;373:2223-33 https://doi.org/.

7. Grigsby TJ, Forster M, Unger JB, et al. Predictors of alcoholrelated negative consequences in adolescents: A systematic review of the literature and implications for future research. J Adolesc 2016;48:18-35 https://doi.org/.

8. Burns S, Jancey J, Crawford G, et al. A cross sectional evaluation of an alcohol intervention targeting young university students. BMC Public Health 2016;16:610 https://doi.org/.

9. Squeglia LM, Tapert SF, Sullivan EV, et al. Brain Development in HeavyDrinking Adolescents. Am J Psychiatry 2015;172:531-42 https://doi. org/.

10. Livingston M, Laslett AM, Dietze P. Individual and community correlates of young people's high-risk drinking in Victoria, Australia. Drug Alcohol Depend 2008;98:241-8 https://doi.org/.

11. Stappenbeck CA, Quinn PD, Wetherill RR, et al. Perceived norms for drinking in the transition from high school to college and beyond. $J$ Stud Alcohol Drugs 2010;71:895-903 https://doi.org/10.15288/jsad. 2010.71.895.

12. Svensson M. Alcohol use and social interactions among adolescents in Sweden: do peer effects exist within and/or between the majority population and immigrants? Soc Sci Med 2010;70:1858-64.

13. Anderson KG, Grunwald I, Bekman N, et al. To drink or not to drink: motives and expectancies for use and nonuse in adolescence. Addict Behav 2011;36:972-9 https://doi.org/. 
14. Liefbroer AC, Billari FC. Bringing norms back in: a theoretical and empirical discussion of their importance for understanding demographic behaviour. Population, Space and Place 2010;16:287-305.

15. Borsari B, Carey KB. Descriptive and injunctive norms in college drinking: a meta-analytic integration. J Stud Alcohol 2003;64:331-41.

16. Kinard BR, Webster C. The Effects of Advertising, Social Influences, and Self-Efficacy on Adolescent Tobacco Use and Alcohol Consumption. J Consum Aff 2010;44:24-43.

17. Martino SC, Collins RL, Ellickson PL, et al. Socio-environmental influences on adolescents' alcohol outcome expectancies: a prospective analysis. Addiction 2006;101:971-83.

18. Nargiso JE, Friend K, Florin P. An Examination of Peer, Family, and Community Context Risk Factors for Alcohol Use and Alcohol Use Intentions in Early Adolescents. J Early Adolesc 2013;33:973-93.

19. Arthur MW, Hawkins JD, Pollard JA, et al. Measuring risk and protective factors for substance use, delinquency, and other adolescent problem behaviors. The Communities That Care Youth Survey. Eval Rev 2002;26:575-601.

20. Core Institute. Core Campus Survey of Alcohol and Other Drug Norms, Southern Illinois University. Carbondale 1996 http://core.siu.edu/surveys.html.

21. Johnston LD, O'Malley PM, Bachman JG. Monitoring the future national survey results on drug use, 1975-2000. Secondary School Students. Bethesda, Maryland: National Institute on Drug Abuse, U.S. Department of Health and Human Services, 2001. vol. 1.

22. Oetting ER, Beauvais F, Edwards R. The American Drug and Alcohol Survey (ADAS). Fort Collins, CO: Rocky Mountain Behavioural Science Institute, 1984.

23. Reboussin BA, Song EY, Wolfson M. Social influences on the clustering of underage risky drinking and its consequences in communities. J Stud Alcohol Drugs 2012;73:890-8 https://doi.org/ 10.15288/jsad.2012.73.890.

24. Carcioppolo N, Jensen JD. Perceived historical drinking norms and current drinking behavior: using the theory of normative social behavior as a framework for assessment. Health Commun 2012;27:766-75.

25. Tarter RE. Evaluation and treatment of adolescent substance abuse: a decision tree method. Am J Drug Alcohol Abuse 1990;16:1-46.

26. Tarter R, Hegedus A. The Drug Use Screening Inventory: Its application in the evaluation and treatment of alcohol and drug abuse... Alcohol, Health and Research World 1991;15:65-75.

27. Winters KC. Henly GA: Personal Experience Inventory (PEI) Test and Manual. In. Los Angeles, CA: Western Psychological Services, 1989.

28. Hildebrand J, Maycock B, Burns S, Howat P, et al. Design of an instrument to measure alcohol-related psychosocial influences in the development of norms among 13-year-old to 17-year-old adolescents. BMJ Open 2013;3:e003571.

29. Bandura A, ed. Social Foundations of Thought and Action: A Social Cognitive Theory. New Jersey: Prentice Hall, 1986.

30. Mundt MP. The impact of peer social networks on adolescent alcoho use initiation. Acad Pediatr 2011;11:414-21 https://doi.org/.

31. Brooks-Russell A, Simons-Morton B, Haynie D, et al. Longitudinal relationship between drinking with peers, descriptive norms, and adolescent alcohol use. Prev Sci 2014:15:1-9.

32. Demartini KS, Carey KB, Lao K, et al. Injunctive norms for alcoholrelated consequences and protective behavioral strategies: effects of gender and year in school. Addict Behav 2011;36:347-53 https://doi. org/.

33. Elek E, Miller-Day M, Hecht ML. Influences of Personal, Injunctive, and Descriptive Norms on Early Adolescent Substance use. J Drug Issues 2006;36:147-72 https://doi.org/.

34. Oostveen T, Knibbe R, De Vries H. Social influences on young adults' alcohol consumption: Norms, modeling, pressure, socializing, and conformity. Addict Behav 1996;21:187-97 https:// doi.org/.

35. Zhang L, Welte JW, Wieczorek WF. Peer and parental influences on male adolescent drinking. Subst Use Misuse 1997;32:2121-36 https://doi.org/.

36. Paredes V, Cantu VC. Graf NM: The Impact of Reality Television on the AlcoholRelated Beliefs and Behaviours of Hispanic College Students. Journal of Alcohol and Drug Education 2013;57:23-45.

37. Litt DM, Stock ML. Adolescent alcohol-related risk cognitions: the roles of social norms and social networking sites. Psychol Addict Behav 2011;25:708-13 https://doi.org/.

38. Zucker RA, Donovan JE, Masten AS, et al. Early developmental processes and the continuity of risk for underage drinking and problem drinking. Pediatrics 2008;121 Suppl 4(Suppl 4):S252-S272 https://doi.org/.

39. Corbin WR, Iwamoto DK, Fromme K. Broad social motives, alcohol use, and related problems: Mechanisms of risk from high school through college. Addict Behav 2011;36:222-30 https://doi.org/.
40. Zamboanga BL, Schwartz SJ, Ham LS, et al. Do alcohol expectancy outcomes and valuations mediate peer influences and lifetime alcohol use among early adolescents? J Genet Psychol 2009;170:359-76 https://doi.org/.

41. Zamboanga BL, Ham LS, Van Tyne K, et al. Alcohol expectancies among adolescent nondrinkers: they may not be drinking now, but they're "thinkin bout it". J Adolesc Health 2011;49:105-7 https://doi.org/.

42. Jones SC, Magee CA. Exposure to alcohol advertising and alcohol consumption among Australian adolescents. Alcohol Alcohol 2011;46:630-7 https://doi. org/.

43. Reed MB, Lange JE, Ketchie JM, et al. The relationship between social identity, normative information, and college student drinking. Soc Influ 2007;2:269-94 https://doi.org/.

44. Rimal RN. Real K: How behaviours are influenced by perceived norms: a test of the theory of normative social behaviour. Communication research 2005;32:389-414 https://doi.org/.

45. Han Y, Kim H, Ma J. School bonds and the onset of substance use among Korean youth: an examination of social control theory. Int $J$ Environ Res Public Health 2015;12:2923-40 https://doi.org/.

46. Orpinas P. Raczynski K: School climate associated with school dropout among tenth graders. Pensamiento Psicologico 2016;14:9-20.

47. McNeely C, Falci C. School connectedness and the transition into and out of health-risk behavior among adolescents: a comparison of social belonging and teacher support. J Sch Health 2004;74:284-92 https://doi.org/.

48. Ryan SM, Jorm AF, Lubman DI. Parenting factors associated with reduced adolescent alcohol use: a systematic review of longitudinal studies. Aust N Z J Psychiatry 2010;44:774-83 https:// doi.org/.

49. Bot SM, Engels RC, Knibbe RA, et al. Friend's drinking behaviour and adolescent alcohol consumption: the moderating role of friendship characteristics. Addict Behav 2005;30:929-47 https://doi. org/.

50. Urberg KA, Luo Q, Pilgrim C, et al. A two-stage model of peer influence in adolescent substance use: individual and relationshipspecific differences in susceptibility to influence. Addict Behav 2003;28:1243-56 https://doi.org/.

51. Kobus K. Henry D: Interplay of network position and peer substance use in early adolescent cigarette, alcohol, and marijuana use. The Journal of Early Adolescence 2009;29:1-20.

52. Streiner DL. Norman GR: Health Measurement Scales: A practical guide to their development and use. 4th edn. Oxford: Oxford University Press, 2008. https://doi.org/.

53. Flesch R: A new readability yardstick. Journal of Applied Psychology 1948;32:221-33 https://doi.org/.

54. Maples P, Franks A, Ray S, et al. Development and validation of a low-literacy Chronic Obstructive Pulmonary Disease knowledge Questionnaire (COPD-Q). Patient Educ Couns 2010;81:19-22 https:// doi.org/.

55. Ham LS, Stewart SH, Norton PJ, et al. Psychometric Assessment of the Comprehensive Effects of Alcohol Questionnaire: Comparing a Brief Version to the Original Full Scale. J Psychopathol Behav Assess 2005;27:141-58 https://doi. org/.

56. Hudson A, Bell W, Hudson T, et al. The Views of Parents and Adolescents on the Granting of Behavioural Autonomy to Adolescents: Some Normative Data. The Australian Educational and Developmental Psychologist 1986;3:6-11 https://doi.org/.

57. Scholte RH, Poelen EA, Willemsen G, et al. Relative risks of adolescent and young adult alcohol use: the role of drinking fathers, mothers, siblings, and friends. Addict Behav 2008;33:1-14.

58. Core Institute, Campus Survey of Alcohol and Other Drug Norms, Southern Illinois University, Carbondale. 2004 http://core.siu.edu/ surveys.html.

59. Baer JS. Effects of college residence on perceived norms for alcohol consumption: An examination of the first year in college. Psychology of Addictive Behaviors 1994;8:43-50.

60. Foley KL, Altman D, Durant RH, et al. Adults' approval and adolescents' alcohol use. J Adolesc Health 2004;35:345.

61. Waters S, Cross D. Measuring students' connectedness to school, teachers, and family: Validation of three scales. School Psychology Quarterly 2010;25:164-77.

62. Kochenderfer BJ, Ladd GW. Peer victimization: cause or consequence of school maladjustment? Child Dev 1996;67:1305-17.

63. Terry DJ, Hogg MA. Group norms and the attitude-behavior relationship: a role for group identification. Personality and Social Psychology Bulletin 1996;22:776-93.

64. White V, Smith G. Australian secondary school students' use of tobacco, alcohol, and over-the-counter and illicit substances in 2008. Victoria: The Cancer Council Victoria, 2009.

65. Comrey A, Lee H. A first course in factor analysis. Hillsdale, NJ: Erbaum, 1992 
66. Coakes S, Steed L, Price J. SPSS: Analysis without anguish: Version 15.0 for Windows. Milton, QLD: John Wiley \& Sons Australia Limited, 2013.

67. Leech N, Caplovitz B, Morgan G. SPSS for intermediate statistics: Use and interpretation. 3rd edn. Hillsdale: NJ: Lawrence Erlbaum Associates, Incorporated, 2008.

68. Field A. Discovering statistics using SPSS. London: Sage, 2005.

69. Dixon JK. Factor analysisMunro BH, Statistical methods for health care research. Philadelphia: Lippincott, 2001:303-31.

70. Cattell RB. The scree test for the number of factors. Multivariate Behav Res 1966;1:245-76.

71. Ledesma RD, Valero-Mora P. Determining the number of factors to retain in efa: an easy-to-use computer program for carrying out parallel analysis. Practical Assessment Research \& Evaluation 2007;12:1-11.

72. Costello AB, Osborne JW. Best practices in exploratory factor analysis: four recommendations for getting the most from your analysis. Practical Assessment, Research \& Evaluation 2005;10:173-8.

73. Barendse MT, Oort FJ, Timmerman ME. Using Exploratory Fcator Analysis to Determine the Dimensionality of Discrete Responses. Structural Equational Modelling. J Multidiscip 2015;22.

74. Hart E, Burns S. The association between witnessed and experienced harm and alcohol consumption amongst students at a large Australian university Health Promotion Journal of Australia, 2016;27:1.

75. Burns S, Crawford G, Hallett J, et al. Consequences of Low Risk and Hazardous Alcohol Consumption among University Students in Australia and Implications for Health Promotion Interventions. Open J Prev Med 2015;05:1-13.

76. Hallett J, Howat PM, Maycock BR, et al. Undergraduate student drinking and related harms at an Australian university: web-based survey of a large random sample. BMC Public Health 2012;12:37.
77. Kypri K, Langley JD, McGee R, et al. High prevalence, persistent hazardous drinking among New Zealand tertiary students. Alcohol Alcohol 2002;37:457-64

78. Bronfenbrenner U, Morris PA. The bioecological model of human development. In: Damon W, Hobolen LRM, Handbook of Child Psychology: Theoretical models of human developmen. 6th edn. New Jersey: John Wiley \& Sons Inc, 2006:793-828.

79. Pedersen ER, Osilla KC, Miles JN, et al. The role of perceived injunctive alcohol norms in adolescent drinking behavior. Addict Behav 2017:67:1-7.

80. Stoddard SA, Bauermeister JA, Gordon-Messer D, et al. Permissive norms and young adults' alcohol and marijuana use: the role of online communities. J Stud Alcohol Drugs 2012;73:968-75.

81. Hummer JF, LaBrie JW, Lac A, et al. Estimates and influences of reflective opposite-sex norms on alcohol use among a high-risk sample of college students: exploring Greek-affiliation and gender effects. Addict Behav 2012;37:596-604.

82. Lewis MA, Neighbors C. Gender-specific misperceptions of college student drinking norms. Psychol Addict Behav 2004;18:334-9.

83. White V, Bariola E. Australian secondary school students' use of tobacco, alcohol, and over-thecounter and illicit substances in 2011. Victoria: The Cancer Council Victoria, 2012.

84. Rymarz R, Cleary A. Kids today: a perspective from students in Australian Catholic schools. Compass:12-18.

85. Rymarz R, Cleary A. Comparing catholic and non-Catholic students in Catholic schools: some implications for understanding secularization. Compass:9-15.

86. AISWA. Independent schools. 2018 https://www.ais.wa.edu.au/ independent-schools (accessed 9 Feb 2018).

87. Roche AM, Bywood P, Freeman T, et al. The social context of alcohol use in Australia. Adelaide: National Centre for Education and Training on Addiction, 2009. 